\title{
NINGUÉM SOLTA A MÃO DE NINGUÉM: PRECISAMOS FALAR SOBRE EDUCAÇÃO INCLUSIVA
}

\author{
NO ONE RELEASES ANYONE'S HAND: WE NEED TO TALK ABOUT INCLUSIVE \\ EDUCATION
}

\section{NADIE SUELTA LA MANO DE NADIE: NECESITAMOS HABLAR DE EDUCACIÓN INCLUSIVA}

Gabriela Viol Valle

E-mail: gabrielaviol@hotmail.com

\begin{abstract}
RESUMO
Este trabalho consiste em uma pesquisa sobre o tema da educação inclusiva e os principais pontos que o norteiam, tais como: a importância da conscientização de todos sobre a educação inclusiva, principais tópicos que precisam ser levados em conta no que diz respeito a esse tipo de educação e aos profissionais envolvidos. Nosso objetivo foi refletir sobre a educação inclusiva, sobre o lugar de alunos com Necessidades Educativas Especiais (NEE) na escola e sobre a atuação do neuropsicopedagogo nesse contexto. Como base teórica, apoiamo-nos no em Marian et al. (2007) e Dresch (2018) para falar sobre educação inclusiva; Correia (1999) e Mazzota (1982) a fim de discorrer sobre quem é o público pertencente aos alunos com NEE; e nos preceitos da Sociedade Brasileira de Neuropsicopedagogia (SBNPP). A metodologia da pesquisa foi de natureza bibliográfica e qualitativa interpretativista e os métodos utilizados foram: a busca por pesquisas anteriores que tratassem sobre o tema e, posteriormente, uma breve análise sobre o curta-metragem Ian - uma estória verídica de inclusão. A partir das discussões e análises, concluímos que o processo de inclusão dos alunos com NEE tem sido pensado e desenvolvido nos últimos anos, no entanto, ainda temos muito caminho e muitas conquistas a serem alcançadas para uma educação inclusiva acessível para todos.
\end{abstract}

PALAVRAS-CHAVE: Educação inclusiva. Neuropsicopedagogo. Necessidades Educativas Especiais.

\section{ABSTRACT}

This work consists of a research on the subject of inclusive education and the main points that guide it such as the importance of raising awareness for special education, main topics that need to be taken into account when considering the special education and the professionals involved. Our objective was to reflect on inclusive education, on the place of students with Special Educational Needs (SEN) in the school and on the role of the neuropsychopedagogist in this context. As a theoretical basis, we rely on Marian et al. (2007) and Dresch (2018) to talk about inclusive education; Correia (1999) and Mazzota (1982) in order to discuss who is the public belonging to students with SEN; and in the precepts of the Brazilian Society of Neuropsychopedagogy (BSNPP). The research methodology was of a bibliographic and qualitative nature and the methods used were the search for previous research that dealt with the theme and, later, a brief analysis on the short, animated film Ian - a true story of inclusion. From the discussions and analyzes we concluded that the process of inclusion of special education students has been thought and developed in recent years, however, we still have a long way and many achievements to be accomplished for an inclusive education accessible to all.

KEYWORDS: Inclusive Education. Neuropsychopedagogue. Special Educational Needs (SEN).

\section{RESUMEN}

Este trabajo consiste en una investigación sobre el tema de la educación inclusiva y los principales puntos que le orientan, tales como: la importancia de la concientización de todos sobre la educación especial, principales tópicos que necesitan ser tomados en cuenta en lo que se relaciona a este tipo de educación y a los profesionales involucrados Nuestro objetivo fue reflexionar sobre la educación inclusiva, sobre el lugar de los estudiantes con 
Necesidades Educativas Especiales (NEE) en la escuela y sobre el papel del neuropsicopedagogo en este contexto. Como base teórica, nos apoyamos en Marian et al. (2007) y Dresch (2018) para hablar de educación inclusiva; Correia (1999) y Mazzota (1982) con el fin de discutir quién es el público perteneciente a los estudiantes con NEE; y en los preceptos de la Sociedad Brasileña de Neuropsicopedagogía (SBNPP). La metodología de investigación fue de naturaleza bibliográfica y cualitativa y los métodos utilizados fueron: la búsqueda por investigaciones anteriores que tratasen sobre el tema e, posteriormente, un breve análisis sobre el curta-metraje Ian - una historia verídica de inclusión. A partir de las discusiones y análisis, concluimos que el proceso de inclusión de los sujetos especiales ha sido pensado y desarrollado en los últimos años, sin embargo, aún tenemos camino y muchas conquistas a ser alcanzadas para una educación inclusiva accesible para todos.

PALABRAS-CLAVE: Educación inclusiva. Neuropsicopedagogos. Necesidades Educativas Especiales (NEE).

\section{INTRODUÇÃO}

Somos tão fortes quando estamos unidos e tão fracos quando estamos divididos.

J.K. Rowling

Durante muito tempo, pessoas com algum tipo de doença/transtorno mental foram tratadas e interpretadas como fora da normalidade (BAIRRÃO et al., 1998, p. 15; CORREIA JUNIOR, VENTURA; 2004, p. 44, 45). Ter algum tipo de condição mental pode significar que tais sujeitos demandem Necessidades Educativas Especiais (NEE) ${ }^{1}$.

Após muitos movimentos que lutaram a favor da desconstrução do estigma do 'doente mental', dando origem à chamada reforma psiquiátrica, observou-se que o indivíduo possuidor de alguma condição mental, para conseguir se desenvolver, precisa, sobretudo, estar inserido na sociedade e não em situação de isolamento. Conforme salienta (BEZERRA Jr., 2007, p. 249) “o movimento antimanicomial é uma das formas de luta contra a exclusão e a favor da tolerância e respeito pela diferença". Desse modo, não deve ser diferente no que diz respeito ao processo de aprendizagem dos alunos com NEE.

Utilizamos neste trabalho o termo "educação inclusiva" com a concepção de que este conceito "busca contemplar a atenção para as diferentes necessidades decorrentes de condições individuais (por exemplo, as deficiências), econômicas ou socioculturais dos alunos" (MARIAN et al., p. 2007, p. 641)

Ser portador de NEE não significa que esses alunos devem ser tratados com discriminação ou de forma excludente. Pelo contrário, após movimentos -como a Conferência Mundial sobre as Necessidades Educativas Especiais, organizado pela Organização das Nações

\footnotetext{
1 “O que o uso deste termo pressupõe é uma mudança de enfoque na análise da problemática da criança passandose a privilegiar a vertente educacional." (Bairrão et al., 1998, p. 23). Mais à frente, falaremos mais detalhadamente acerca do público que compõe o grupo de alunos com NEE.
} 
Unidas para Educação, Ciência e Cultura (UNESCO), em 1994, que contou com a participação do Brasil e da elaboração da "Declaração de Salamanca" (OLIVEIRA, AMARAL, 2004, p. 5; MARIAN et al., 2007, p. 641)- um novo olhar surgiu para os alunos com NEE. A Declaração de Salamanca definiu que um ambiente escolar inclusivo é um "local onde todos os alunos aprendem juntos, sempre que possível, independentemente das dificuldades e diferenças que apresentem" (DECLARAÇÃO DE SALAMANCA, 1994)

Nesse cenário, para que haja a inclusão de forma integrada do sujeito com NEE nas salas de aula, alguns aspectos e alguns profissionais tornam-se fundamentais. A promoção da conscientização dos demais alunos sobre a conjuntura do aluno com NEE e da importância que eles têm no processo de incluí-los são pontos cruciais. Em relação aos profissionais, destacamos a essencialidade da atuação do neuropsicopedagogo, em conjunto com o trabalho da esquipe escolar. Assim, discutimos de forma mais detalhada sobre esses dois tópicos nas seções dois e três desta pesquisa.

Este trabalho é de natureza bibliográfica e qualitativa interpretativista e a metodologia foi pautada na reflexão de pontos indispensáveis sobre o tema da educação inclusiva e em uma breve análise do curta-metragem intitulado Ian - uma estória verídica de inclusão.

Nosso objetivo foi refletir sobre a educação inclusiva, sobre o lugar de alunos com Necessidades Educativas especiais (NEE) na escola e sobre a atuação do neuropsicopedagogo. Mais especificamente, buscamos pensar sobre o processo de inclusão do aluno com NEE e as questões problematizadoras que permeiam esse contexto, bem como a importância de um trabalho em equipe, além da participação da família e dos demais alunos.

Como base teórica, baseamo-nos no que propõem Marian et al. (2007), Dresch (2018) sobre educação inclusiva; Correia (1999), Mazzota (1982) sobre quem é o público pertencente aos alunos com NEE; e nos preceitos da Sociedade Brasileira de Neuropsicopedagogia (SBNPP). Além disso, outros trabalhos feitos na área nos serviram de apoio.

\section{EDUCAÇÃO INCLUSIVA: UMA REFLEXÃO SOBRE O AMBIENTE ESCOLAR NO DESENVOLVIMENTO DE ALUNOS COM NEE}

O desenvolvimento do processo de aprendizagem de uma criança é uma tarefa desafiadora para todos os envolvidos. Desse modo, tanto os professores quanto os outros membros da equipe escolar precisam ter um bom preparo para conseguir lidar com as diversas demandas que surgem no âmbito escolar, pois “a formação deficitária traz sérias consequências 
à efetivação do princípio inclusivo, pois este pressupõe custos e rearranjos posteriores que poderiam ser evitados" (SANT’ANA, 2005, p. 228).

Considerando que cada indivíduo é singular e que, portanto, pode apresentar diferentes respostas no processo de aprendizagem, é importante que diversas estratégias sejam criadas para que todas as crianças tenham um bom suporte no seu ensino, como, por exemplo, o recurso de atividades em grupo, que além de incluir alunos pode fazer com que eles tenham bons desempenhos nos seus processos. Desse modo, conforme pontua Ramos (2001, p. 4) "a colaboração quando bem utilizada pode ser uma estratégia importante para superar as dificuldades encontradas na sala de aula e para promover a aprendizagem".

Para que possamos refletir sobre o processo de aprendizagem dos alunos com NEE é importante que tenhamos esclarecido quem compõe esse grupo e, consequentemente, a quem estamos nos referindo neste trabalho. Segundo Correia (1999, p. 19) esses educandos são aqueles que "apresentam um problema de aprendizagem durante o seu percurso escolar, o que exige uma atenção mais específica e uma gama de recursos educativos diferentes daqueles necessários para os companheiros da mesma idade".

É muito comum associarmos a imagem da escola como um ambiente de aprendizado de conteúdos pragmáticos específicos que contemplam as ementas dos cursos. No entanto, o modo de ensino, as trocas entre as pessoas, o incentivo de bons comportamentos também são fatores que devem ser desenvolvidos, pois a escola é um espaço onde os sujeitos formam as suas convicções e seus valores para vivenciarem experiências sociais de modo geral. Dessa forma, "a escola é o lugar onde as adaptações curriculares devem ser feitas com muita responsabilidade, pois dali sairá o aluno realmente inserido no contexto social." (BRESCH, 2018, p. 111)

A atenção e conhecimento de toda a equipe escolar sobre as especificidades dos alunos é essencial para que haja um bom funcionamento no desenvolvimento da aprendizagem deles. No entanto, é significativo destacar o papel do professor nesse cenário, principalmente na préescola, em que o aluno está em fase de desenvolvimento e que o professor costuma assumir a turma praticamente em tempo integral.

Diante disso, podemos dizer que a função do professor é formar o aluno, também, de forma integral, como cidadão, não sendo diferente, é claro, com os alunos com NEE. Por causa disso, torna-se indispensável que o professor esteja em constante busca e aprendizado, para que esteja cada vez mais preparado para enfrentar eventuais situações dos alunos no dia a dia, 


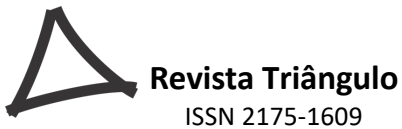

sobretudo daqueles que possuem NEE, que demandam maior atenção. Cabe ao professor buscar alternativas para promover um ensino em que os alunos com NEE tem as mesmas oportunidades dos outros alunos e que seja, consequentemente, incluído. Assim, conforme pontua Lima (2017, p. 92)

\begin{abstract}
A proposta que se impõe é a igualdade de possibilidades, como forma de promover a inclusão de todos e em todos os setores sociais, pensando na formação de um homem capaz de apreender o mundo em que vive em condições de transformá-lo e não somente de reproduzi-lo, e essa formação perpassa pela obtenção de habilidades, atitudes e valores, que são oferecidas pelo professor, por isso é tão importante o seu processo contínuo de formação.
\end{abstract}

O tema da inclusão escolar é um tópico indispensável para ser pensado e refletido. No entanto, por muito tempo vivenciamos ambientes escolares excludentes, em que os alunos com NEE deveriam apenas conviver com outros iguais a eles. O documento das Diretrizes Nacionais Curriculares de educação básica de 2001 apresentou, inclusive, a possibilidade da criação da chamada "Classe Especial", a qual previa o encaminhamento de alunos nas seguintes condições: "[...]quando se detectar nesses alunos grandes defasagens idade/série; quando faltarem aos alunos experiências escolares anteriores, dificultando o desenvolvimento do currículo em classe comum" (BRASIL, 2001, p. 53). O motivo disso pode ter relação com o fato de que o ato de incluir um aluno com NEE não significa apenas colocá-lo em uma turma regular, mas sim dar devida assistência para que ele, considerando suas especificidades, e promovendo um bom desenvolvimento em seu aprendizado. Assim, como explica Dresch (2018, p.111)

incluir não é somente fazer de conta que o aluno está assistido porque simplesmente está dentro da sala de aula ou do contexto escolar. Vai muito além disso, vai do olhar dos professores, familiares e equipe como um todo; vai de entender as dificuldades e as limitações do aluno; vai ao encontro da nova visão educacional dos dias atuais.

É fundamental que o olhar de todos que lidam com os alunos com NEE seja bastante empático e busque o melhor tratamento, tendo em vista que o próprio termo sugerido, de 'inclusão escolar', seja alcançado. Para que os alunos com NEE se sintam parte e acolhidos, é indispensável que haja uma flexibilização no currículo de modo que este se adapte tanto às necessidades desse público quanto às suas capacidades. Portanto, invés da ideia de adaptação curricular que, segundo Garcia (2007), essa organiza as atividades educacionais de acordo com diagnósticos e prognósticos clínicos sobre o desenvolvimento de alunos incluídos. (SILVA, MELLO, 2018, p. 761) 


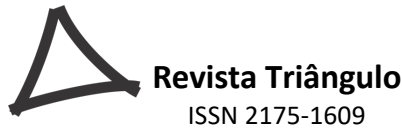

Para além das questões sociais implicadas na temática da educação inclusiva, um tópico que tem sido inserido nos estudos sobre aprendizagem de alunos com NEE é a chamada Neuroeducação, que propõe estudos que sintetizam a neurociência e a educação. Cosenza e Guerra (2011, p. 142 apud SILVA, MELLO, 2018, p. 760) salientam que "as Neurociências estudam os neurônios e suas moléculas constituintes, os órgãos do sistema nervoso e suas funções específicas, e também as funções cognitivas e o comportamento que são resultantes da atividade dessas estruturas". Sendo assim, embora não nos atenhamos de forma profunda a esse tema neste trabalho, notamos que compreender aspectos que permeiam as Neurociências pode ser, também, um caminho para refletir acerca da educação de alunos com NEE e de seus desempenhos.

Portanto, alguns pontos são imprescindíveis para tornar a educação inclusiva possível, além de garantir um bom desenvolvimento no processo de aprendizagem dos alunos incluídos. Dentre eles, destacamos a importância de que os alunos com NEE tenham assistência e um olhar compreensivo por parte dos educadores e de toda a sua equipe, levando em conta, assim, suas limitações e o que é viável dentro de suas possibilidades. Além disso, salientamos, também, sobre a relevância de que a equipe esteja em um processo constante de indagação, buscando sempre novos recursos e perspectivas para promover um ensino de qualidade para os alunos com NEE, além de conscientizar os demais.

\section{A NEUROPSICOPEDAGOGIA E A IMPORTÂNCIA DO TRABALHO EM EQUIPE NO PROCESSO DE INCLUSÃO}

A neuropsicopedagogia, como o próprio nome diz, é uma área transdisciplinar, isto é, que se reveste de diferentes áreas de estudo. Segundo a Sociedade Brasileira de Neuropsicopedagogia (SBNPP),

\footnotetext{
A Neuropsicopedagogia é uma ciência transdisciplinar, fundamentada nos conhecimentos da Neurociências aplicada à educação, com interfaces da Pedagogia e Psicologia Cognitiva que tem como objeto formal de estudo a relação entre o funcionamento do sistema nervoso e a aprendizagem humana numa perspectiva de reintegração pessoal, social e educacional.. (Art. 10. Resolução 03/2014-SBNPp)
}

Além disso, a sociedade esclarece, também que "a atuação do Neuropsicopedagogo tem o objetivo de promover uma educação de qualidade, com foco no trabalho efetivo da Educação Inclusiva, bem como o atendimento prioritário às crianças e jovens com dificuldades de aprendizagem" (SBNPP, 2016, s/p). 


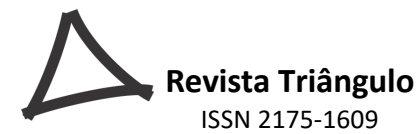

Dentre os aspectos que o neuropsicopedagogo avalia, estão, “(...) áreas da leitura, escrita, compreensão e intelecção de texto, aritmética, atenção e funções executivas, observação psicomotora e instrumentos para investigar os pré-requisitos envolvidos na alfabetização" (RUSSO, 2015 apud BRESCH, 2018, p. 41). Além disso, a função desse profissional diz respeito à mediação de situações intencionais, além de analisar metodologias que precisam ser adotadas para que as dificuldades dos alunos com NEE em sua aprendizagem sejam superadas (CASTRO, SILVA, 2020, p. 103)

Considerando que o público ao qual o neuropsicopedagogo é voltado possui uma demanda maior do que as demais crianças, é importante que sejam elaboradas estratégias diversas que consigam traçar soluções para as exigências existentes no desenvolvimento, sobretudo da aprendizagem, dos alunos com NEE. Desse modo, "um dos papéis fundamentais do neuropsicopedagogo é trabalhar com estratégias de aprendizagem variadas, definindo atividades ou operações mentais que o sujeito pode executar para facilitar e melhorar sua aprendizagem" (RUSSO, 2015, p. 125 apud BRESCH, 2018, p. 42).

Um ponto imprescindível para ser destacado é a essencialidade do trabalho em equipe para atuar no processo de aprendizagem dos alunos com NEE. Embora nem todas as crianças apresentem as mesmas queixas, focar no desenvolvimento delas de um modo geral pode ser positivo como um todo, uma vez que trabalhando as demandas a nível macro, o nível micro pode ser, consequentemente, alcançado. Dessa forma, é preciso que essa equipe pense, conjuntamente, qual é a melhor forma de agir diante de determinada demanda. Assim, como aponta Bresch (2018, p. 42),

O neuropsicopedagogo, quando recebe o laudo dos demais profissionais, cria um plano de ação que deve conter os objetivos a serem atingidos no início, no meio e no final do acompanhamento do sujeito, visando à melhoria dos aspectos que apresentaram dificuldades.

Para que os profissionais consigam criar um plano de ação que vá auxiliar os alunos com NEE de modo que eles tenham um bom processo de aprendizagem, é indispensável que eles compreendam como se dá o desenvolvimento psicológico ${ }^{2}$ desses sujeitos. Assim, Carneiro e Cardoso (2009, p. 461) explicam que

O desenvolvimento psicológico se dá por meio de uma interação dinâmica e contínua das experiências sociais e ambientais e por isso é necessário, não só identificar os

\footnotetext{
${ }^{2}$ Ressaltamos que ao tratarmos de 'desenvolvimento psicológico' estamos focando em seu âmbito social e não estrutural biológico, isto é, levantamos aqui a importância das questões sociais, tal como a inclusão, para o desenvolvimento do aluno.
} 
fatores que interferem nesse processo, mas também sua influência. Padrões rudimentares de atividade neural fornecerão a base do desenvolvimento psicológico da criança.

Podemos dizer, então, que o processo de inclusão do aluno com NEE é um fator essencial para o desenvolvimento, uma vez que ao estar incluído no meio interacional poderá viver experiências sociais tais como todos os outros alunos, o que permitirá o seu desenvolvimento psicológico. Todavia, ainda que haja um processo de inclusão, é evidente que o aluno com NEE exige uma adaptação para se desenvolver/aprender, visto que ele apresenta determinadas condições que fazem com que seus processos ocorram diferentemente dos demais alunos ou ao menos em um espaço de tempo ou forma distinta. Portanto, é necessário pensar em

estratégias de flexibilidade curricular relacionadas à inclusão educacional centradas na perspectiva de "diversificar as opções de aprendizagem, promover ajuda entre as crianças, oferecer suporte para as dificuldades apresentadas pelos alunos e desenvolver relacionamentos mais próximos com as famílias e a comunidade". (GARCIA, 2007, p. 13 apud SILVA, MELLO, 2018, 761)

Estimular um processo de aprendizagem conjunto entre os alunos com NEE, seus familiares, os demais alunos, os professores e a comunidade de um modo geral é o caminho para a promoção de um aprendizado e amadurecimento do aluno com NEE. A palavra inclusão -“do verbo incluir (do latim includere), no sentido etimológico, significa conter em, compreender, fazer parte de, ou participar de" (DICIONÁRIO ONLINE INFORMAL)- já nos remete a ideia de que ao propormos uma metodologia de inclusão escolar, estamos viabilizando um ensino em que o aluno faz parte, isto é, participa ativamente do seu processo de aprendizagem.

A visão e a interpretação que se faz do sujeito que possui uma condição especial é um dos itens que precisa ser refletido. Por muito tempo, acreditou-se que um aluno com NEE era alguém incapaz, não havendo possibilidade de se desenvolver. Assim, Mazzota (1982, p. 3 apud GAIA, 2017, p.3) esclarece que

Um consenso social pessimista, fundamentado essencialmente na idéia de que a condição de 'incapacitado, 'defíciente', 'inválido' é uma condição imutável, leva à completa omissão da sociedade em relação à organização de serviços para atender às necessidades individuais específicas dessa população.

Incluir o aluno com NEE de forma integral na sociedade é um dos pontos fundamentais para que ele consiga se desenvolver. A não exclusão desse grupo é necessária para que todos possam deixar essa visão apontada por Mazzota (1982) de lado e para que o próprio sujeito 
possuidor de uma NEE consiga se enxergar de maneira positiva, já que isso pode interferir diretamente no seu progresso.

É muito possível que enquanto o indivíduo que faz parte do grupo de sujeitos com NEE for visto e se ver como uma pessoa limitada será dessa forma que ele agirá. Entretanto, havendo uma visão otimista de que ele possa progredir, tanto quanto qualquer outra pessoa, ainda que necessite de diferentes condições e de um maior espaço de tempo, então ele poderá bons resultados em seus processos de aprendizagem.

Portanto, cabe à equipe, aos familiares e aos demais alunos, pensar na melhor forma de incluir o aluno com NEE. Todos fazendo parte do processo de inclusão pode fazer com que esses alunos se sintam acolhidos e, consequentemente, motivados, apresentando melhores resultados na sua aprendizagem e no seu bem-estar.

\section{METODOLOGIA}

A metodologia deste trabalho foi de natureza bibliográfica e qualitativa interpretativista, as quais são pautadas, respectivamente, na leitura de trabalhos anteriores e na reflexão sobre o tema escolhido a partir de ângulos pessoais e cuja função é ter um olhar explorador diante do que é construído socialmente, no dia a dia. Denzin e Lincoln (2006, p.17) destacam justamente essa ideia, explicando que "a pesquisa qualitativa envolve o estudo do uso e a coleta de uma variedade de materiais empíricos (...) que descrevem momentos e significados rotineiros e problemáticos na vida dos indivíduos".

Em um primeiro momento, realizamos os levantamentos de dados acerca de tópicos importantes que envolvem a temática da pesquisa e fizemos uma análise interpretativista sobre eles.

E em um segundo momento, selecionamos uma animação para fazer uma breve análise relacionando-a com os conceitos discutidos anteriormente. A animação selecionada foi o curtametragem cujo título é Ian - uma estória verídica de inclusão. A obra relata a história de um menino que possui paralisia e se vê e sente excluído das outras crianças. A ideia principal foi fazer um paralelo entre a posição ocupada por Ian e pelos demais personagens da história com os demais alunos, os alunos com NEE e os envolvidos no processo de aprendizagem deles.

Portanto, os métodos utilizados nesta pesquisa foram: levantamento de dados bibliográficos, que abordam temas da educação inclusiva, neuropsicopedagogia e trabalho 
conjunto; e uma breve análise da animação intitulada Ian - uma estória verídica de inclusão com base nos apontamentos teóricos feitos anteriormente.

\section{UMA BREVE ANÁLISE DO CURTA METRAGEM IAN - UMA ESTÓRIA VERÍDICA DE INCLUSÃO}

Conforme vimos anteriormente, repensar o contexto dos alunos com NEE é fundamental para que haja uma boa atuação profissional e um processo de inclusão escolar efetivo. Muitos projetos têm sido elaborados nos últimos anos com objetivo de promover a inclusão e de sensibilizar a sociedade como um todo para esse tema.

A partir do advento da tecnologia e da grande possibilidade de divulgação via internet, muitas páginas, sites e canais do Youtube têm buscado apresentar o tema ao mundo. O curta metragem, Ian - uma estória verídica de inclusão, por exemplo, é uma obra criada pela Fundação IAN que "nasceu em 2012 movida pelo amor de uma mãe que ousou sonhar com um mundo mais inclusivo." 3

Segundo dados do próprio site, "a Fundação IAN promove a inclusão trazendo a deficiência para os lares e fornecendo ferramentas para que todos possamos ter uma participação ativa na construção de uma sociedade mais inclusiva". Além disso, os criadores da fundação salientam que a "estratégia é desenvolver ferramentas e conhecimentos específicos sobre deficiência e inclusão e gerar ações de mobilização e conscientização para toda a sociedade".

Desse modo, a animação, criada e divulgada pela fundação, selecionada para este trabalho, conta a história de "uma criança que quer alcançar o mundo com uma mensagem de amor". No vídeo, o personagem principal, Ian, que sofre de paralisia, mostra-se a todo o momento na tentativa de estar junto das outras crianças, mas acaba sempre ficando triste quando percebe que não é acolhido por eles.

Em vários momentos do vídeo, notamos a dificuldade de Ian ao tentar ser como os outros colegas, tentando andar e brincar como eles, mas sempre sendo trazido de volta para a sua realidade. O bullying também está presente no vídeo, em momentos em que as outras crianças riem de Ian ao verem-no tentando agir como elas, como podemos observar nos minutos 2:59 e 5:35. Essas passagens marcam o reforçamento do que destaca Mazzota (1982) acerca do

\footnotetext{
${ }^{3}$ Todos os dados explicativos sobre a Fundação Ian foram retirados do próprio site do projeto, que pode ser acessado em: $<$ https://www.fundacionian.com/ $>$.
} 
olhar pessimista para os alunos com NEE. Enquanto a visão de que esse aluno está fora da normalidade permanecer e for reforçada socialmente, haverá uma corroboração para que eles se sintam incapazes, excluídos e isso, consequentemente, poderá afetar no desenvolvimento dessas crianças. Embora a situação que está sendo representada por Ian seja fora da sala de aula, a concepção de Ramos (2001) acerca da relevância da colaboração entre as crianças pode ser uma estratégia positiva para o desenvolvimento e aprendizado do aluno com NEE.

A divisão e o processo de exclusão de Ian em relação aos demais colegas é marcado pela grade presente no parque em que estão brincando. A todo o momento, Ian é 'puxado' de volta para a sua cadeira, saindo do espaço compartilhado em que as crianças estão (1:30, 3:30). Nesse contexto, podemos fazer uma analogia com a forma como, muitas vezes, são enquadrados nas escolas os alunos com NEE, de forma segregatória, conforme vimos anteriormente em uma iniciativa das Diretrizes Nacionais Curriculares de 2001 que determinou a criação da "Classe Especial” (BRASIL, 2001).

O desfecho da animação se dá com as crianças segurando a mão de Ian (5:52), para que ele não voltasse para a sua cadeira de rodas e continuasse com elas no parque. O momento é marcado, de forma emocionante, com todos fazendo força, segurando a mão dele, para fazê-lo ficar. No entanto, ainda que com todo esforço, elas não conseguem fazer com que Ian fique dentro do parque, e acabam sendo levadas para o lado de fora (6:30). Esse momento do vídeo possui uma representatividade muito grande da importância da consciência e da aceitação das demais crianças sobre a condição do menino Ian e de todas as outras crianças que possuem alguma NEE. Esse trecho do vídeo expressa a essencialidade de que todos façam parte do processo, bem como os outros alunos e a comunidade como um todo, como destaca Garcia (2007), tanto no que diz respeito ao processo de inclusão quanto ao de desenvolvimento da criança com NEE. Além disso, o fato de as outras crianças não conseguirem fazer Ian ficar no ambiente delas, mas sim, serem puxadas para a realidade dele, pode representar, também, a relevância que tem trazer a realidade dos alunos com NEE não só para os demais alunos e para a escola, como também para a sociedade.

Por fim, todos ficam no mesmo local e brincam juntos, mostrando o resultado do processo de inclusão, que como bem destaca Dresch (2018), é algo que envolve o social e não só as questões de sala de aula.

Sobre a postura da mulher que está cuidando de Ian, podemos fazer uma análise interpretativa de que ela possa estar representando o papel de sua mãe ou também de uma 
profissional da área de educação designada a cuidar de um aluno com NEE. Considerando a personagem ocupando o lugar da mãe de Ian, reforçamos a importância da presença do familiar no processo de aprendizagem do aluno com NEE (GARCIA, 2004; DRESCH, 2018). E, ao pensarmos na figura da mulher como uma profissional que trabalha com alunos com NEE, e considerando que sua postura não demonstrou ações que se voltassem para a inclusão e ensino, destacamos a importância de que os profissionais da área tenham uma formação adequada para atuar com esse público, uma vez que o desconhecimento do profissional pode gerar consequências ao princípio inclusivo (SANT'ANA, 2005).

O título deste trabalho Ninguém solta a mão de ninguém: precisamos falar sobre educação inclusiva foi motivado pela forma como foi expressado no vídeo selecionado a necessidade de que haja um trabalho conjunto, tanto da equipe escolar, quanto dos familiares e dos outros alunos para que a inclusão dos alunos com NEE aconteça. A forma como Ian tenta permanecer junto as outras crianças, mas acaba sendo trazido de volta para a sua cadeira de rodas e, consequentemente, para a sua realidade, pode ser uma analogia representativa da luta do aluno com NEE para conseguir estar incluído. Esse contexto pode estar ser colocado em paralelo com a luta antimanicomial que busca a tolerância e o respeito pela diferença, além de vencer a exclusão (Bezerra Jr., 2007). Além disso, a 'puxada' final das crianças que vão até Ian pode significar uma sensibilização sobre o tema, em que torna possível que essa luta ganhe mais espaço socialmente, conforme descrito, no trecho final do título deste trabalho "precisamos falar sobre educação inclusiva".

Assim, podemos perceber que com a iniciativa do projeto os criadores “(...) conseguiram transformar a dor em ação para quebrar as barreiras do isolamento que muitas vezes sofrem as pessoas com deficiência e transmitir que no caminho da inclusão não há tempo a perder". Ademais, a obra é um ótimo recurso para ser apresentado em movimentos que busquem a inclusão dos alunos com NEE e para nos fazer pensarmos sobre o tema com um olhar crítico, conforme buscamos fazer neste trabalho.

\section{CONSIDERAÇÕES FINAIS}

A partir das discussões sobre as temáticas da educação inclusiva, do trabalho do neuropsicopedagogo junto com a equipe escolar, com os familiares e com as demais crianças, chamamos atenção para a indispensabilidade de falarmos sobre a temática da inclusão 
educacional de alunos com NEE. A partir das leituras fica evidente que esses alunos precisam e devem ter uma maior atenção que atendam às suas necessidades para estarem incluídos (MARIAN, et al., 2007).

O destaque para a importância de um trabalho conjunto se dá na medida em que a partir disso já estamos contemplando ao menos uma parte do processo de inclusão, visto que há uma ação colaborativa. Assim, revisitando a epígrafe que abre este trabalho, reforçamos, então, a ideia de que a inclusão dos alunos com NEE no âmbito da educação retrata fortemente o que pontua J.K. Rowling: Somos tão fortes quando estamos unidos e tão fracos quando estamos divididos. Tal fator incentivou, também, a ideia do título deste trabalho, o qual retrata a relevância de uma atuação em que a causa é de todos e não só dos alunos com NEE.

Uma visão negativa e o processo de exclusão perante os alunos com NEE pode causar resultados muito negativos tanto para o seu desenvolvimento pessoal quanto no quesito da aprendizagem (MAZZOTA, 1982). A ação de incluir tornou-se aspecto fundamental no ensino e é dever da escola promover a inclusão, seja através de palestras de conscientização, projetos extraclasses, trazendo essa pauta para as aulas etc.

Portanto - com base na breve análise do curta-metragem Ian, uma estória verídica de inclusão - podemos concluir o que tem apontado as pesquisas sobre o desenvolvimento e aprendizagem de alunos com NEE: o processo de inclusão é fundamental para que a aprendizagem seja proporcionada a esse público de forma integral. Tal proposta visa, acima de tudo, a igualdade de possibilidades para esses alunos não só como estudantes, mas como seres humanos e sociais (LIMA, 2017).

\section{REFERÊNCIAS}

BAIRRÃO et al. Os alunos com necessidades especiais: subsídios para o Sistema de Educação. $1^{a}$ edição. Conselho Nacional de Educação, 1998. BEZERRA JR, B. Desafios da Reforma Psiquiátrica no Brasil. PHYSIS: Rev. Saúde Coletiva, Rio de Janeiro, 17(2):243-250, 2007. DOI: https://doi.org/10.1590/S0103$73312007000200002 \quad$ Disponível https://www.scielo.br/j/physis/a/H4wVY4ZDk9nKqdGsdzyJkWg/?lang=pt\&format=pdf $>$. Acesso em: 22 ago. 2021. BRASIL. Diretrizes Nacionais Para a Educação Especial na Educação Básica / Secretaria de Educação Especial. MEC; SEESP, 2001. Disponível em:< http://portal.mec.gov.br/seesp/arquivos/pdf/diretrizes.pdf>. Acesso em: 21 ago. 2021. 
BRASIL. RESOLUÇÃO SBNPp N 03/2014. Disponível em: http://www.sbnpp.com.br/wpcontent/uploads/2014/09/C\%C3\%B3digo-de-\%C3\%89tica-e-T\%C3\%A9cnico-Profissionalda-Neuropsicopedagogia-SBNPp.pdf. Acesso: 20 de ago. 2021.

BRASIL. RESOLUÇÃ̃O SBNPp. NOTA TÉCNICA Nº 01/2016. Disponível em: Acesso em: 20 de ago. de 2021. Disponível em: < https://www.sbnpp.org.br/arquivos/notas tecnicas.pdf $>$ Acesso em: 22 ago. 2021.

BRESCH, F. Teoria e Prática da Neuropsicopedagogia. 1 ed. Curitiba [PR] : IESDE Brasil, 2018.

CARNEIRO, R.R. CARDOSO, F.B. Estimulação do desenvolvimento de competências funcionais hemisféricas em escolares com dificuldades de atenção: uma perspectiva neuropsicopedagógica. Rev. Psicopedagogia, 2009. ISSN: 0103-8486 Disponível em:< http://pepsic.bvsalud.org/scielo.php?script=sci_arttext\&pid=S0103-84862009000300013>.

Acesso em: 22 ago. 2021.

CORREIA, L. M. Alunos com Necessidades Educativas Especiais nas Classes Regulares. Colecção Educação Especial. Porto: Porto Editora, 1999.

CORREIA JUNIOR R., VENTURA, C. A. Tratamento de portadores de transtorno mental no Brasil. R. Dir. sanit., São Paulo v.15 n.1, p. 40-60, mar./jun. 2014. ISSN: 1935-2001 DOI: https://doi.org/10.1590/S0104-07072010000200008 Disponível em:< https://www.scielo.br/j/tce/a/tznsCBgcPVVMzGN8yy678Ck/?lang=pt\&format=pdf $>$. Acesso em: Acesso em: 21 ago. 2021.

CASTRO, F.S.L., SILVA, S.V. A atuação do neuropsicopedagogo no empoderamento da $\begin{array}{lllll}\text { aprendizagem. } & \text { Revista } & \text { Mythos, } & 102-114, & 2020\end{array}$ https://doi.org/10.36674/mythos.v12i2.314 Disponível em: https://periodicos.unis.edu.br/index.php/mythos/article/view/314/277>. Acesso em: 21 ago. 2021.

DENZIN, N.; LINCOLN, Y. S. e colaboradores. O planejamento da pesquisa qualitativa: teorias e abordagens. 2. ed. Porto Alegre: Artmed, [2003] 2006.

DICIONÁRIO INFORMAL. Inclusão. Disponível em: $<$ https://www.dicionarioinformal.com.br/significado/inclus $\% \mathrm{C} 3 \% \mathrm{~A} 3 \mathrm{o} / 3775 />$. Acesso em: 02 fev. 2021.

FUNDACIÓN IAN. Ian- uma estória verídica de inclusão. 2018. Disponível em: $<$ https://www.fundacionian.com/corto.html >. Acesso em: 20 jan. 2021.

GAIA, R.S.P. Educação Especial no Brasil: análises e reflexões. Revista Transversal, 2017. Disponível em: $<$ http://uniesp.edu.br/sites/_biblioteca/revistas/20170719100610.pdf $>$. Acesso em: 20 jan. 2021.

MARIAN A. L et al. Educação Inclusiva no Ensino Superior: Um Novo Desafio. Psicologia Ciência e Profissão, 2007, 27 (4), 636-647. DOI: https://doi.org/10.1590/S1414$98932007000400006 \quad$ Disponível em:< https://www.scielo.br/j/pcp/a/bv8ZgTdG4C7VMNZXzrDXdcz/?lang=pt\&format=pdf $>$.

Acesso em: 20 ago. 2021.

LIMA, F.R. Sentidos da intervenção neuropsicopedagógica nas dificuldades de aprendizagem na pré-escola. Revista Multidisciplinar em Educação, v.4, n.7, p. 78-95, 2017. DOI: http://dx.doi.org/10.26568/2359-2087.2017.2012 Disponível em:< https://periodicos.unir.br/index.php/EDUCA/article/view/2012>. Acesso em: 20 ago. 2021. OLIVEIRA, M.A.M., AMARAL, C.T. Políticas públicas contemporâneas para a educação especial: inclusão ou exclusão?. 27 Reunião Anual da Anped. GT: Educação Especial /n.15, 2004. Disponível em: $<$ https://anped.org.br/biblioteca/item/politicas-publicas-contemporaneaspara-educacao-especial-inclusao-ou-exclusao $>$. Acesso em: 20 ago. 2021. 
RAMOS, D.K. Integrando as diferenças: crianças com necessidades especiais no ensino regular. Revista do Centro de Educação, Cadernos: edição: 2005 - № 26. ISSN: 1984-686X DOI:http://dx.doi.org/10.5902/1984686X https://periodicos.ufsm.br/educacaoespecial/article/view/4408>. Acesso em: 22 ago. 2021. SANT'ANA, I.M. Educação inclusiva: concepções de professores e diretores. Psicologia em Estudo, Maringá, v. 10, n. 2, p. 227-234, mai./ago. 2005. DOI: https://doi.org/10.1590/S141373722005000200009 Disponível

em:< https://www.scielo.br/j/pe/a/TGkrQ6M6vvXQqwjvLmTFrGw/?lang=pt\&format=pdf $>$.

Acesso em: 20 ago. 2021.SILVA, L.G. MELLO, E.M.B. Fundamentos de neurociência presentes na inclusão escolar: vivências docentes. Revista Educação Especial, v. 31, n. 62, 2018. ISSN: 1984-686X DOI: http://dx.doi.org/10.5902/1984686X Disponível em: $<$ https://periodicos.ufsm.br/educacaoespecial/article/view/28388>. Acesso em: 17 de jan. 2021.

UNESCO. Declaração de Salamanca e enquadramento da acção na área das necessidades educativas especiais. Salamanca, Espanha, 1994. 